\title{
Knowledge management for effective and ethical management of public schools: Perspectives from South Africa
}

\author{
Norma RA Romm* \\ Department of Adult Education and Youth Development, University of South Africa, \\ ORCID: 0000-0002-1722-9720 \\ Bongani I. Nkambule \\ Department of Educational Leadership and Management, University of South Africa \\ ORCID: 0000-0001-9022-0960
}

\begin{tabular}{|c|c|}
\hline & \\
\hline $\begin{array}{l}\text { Received: } \\
20.10 .2021\end{array}$ & $\begin{array}{l}\text { knowledge management in the arena of public schooling, with reference } \\
\text { to a multiple case study involving three schools in Emalahleni Circuit } 1 \text {, }\end{array}$ \\
\hline $\begin{array}{l}\text { Received in revised form: } \\
17.12 .2021\end{array}$ & $\begin{array}{l}2 \text { and } 3 \text { in South Africa. Teachers, HoDs, administrative clerks, and } \\
\text { principals ( } 20 \text { participants altogether) were interviewed in depth } \\
\text { concerning their understandings of knowledge management. We }\end{array}$ \\
\hline $\begin{array}{l}\text { Accepted: } \\
21.12 .2021\end{array}$ & $\begin{array}{l}\text { explicate Nonaka and colleagues' model of knowledge management, } \\
\text { which they developed to apply to business and public organizations and }\end{array}$ \\
\hline Key & which is considered seminal in the literature on knowledge management. \\
\hline $\begin{array}{l}\text { ba principles, } \\
\text { collective orientation, } \\
\text { knowledge construction, } \\
\text { shared space, } \\
\text { sociocultural milieu, } \\
\text { social responsibility, } \\
\text { stakeholder engagement, } \\
\text { Ubuntu. }\end{array}$ & $\begin{array}{l}\text { It is tied to (Japanese) principles of ba - where people recognize their } \\
\text { occupation of a shared space with others. We relate this model to a } \\
\text { discussion on the applicability of the African concept of Ubuntu to the } \\
\text { knowledge management practices in the selected public schools. We use } \\
\text { these cases to consider Ubuntu-directed knowledge management as a } \\
\text { process of developing sharedness of purpose among the stakeholders } \\
\text { within the schools (internal stakeholders) and outside thereof (in the } \\
\text { wider community and society). We indicate to what extent and in what } \\
\text { ways the participants experienced knowledge management in this way. }\end{array}$ \\
\hline
\end{tabular}

\section{Introduction: Linking Effective Management to Ethical Considerations}

Moloi suggests that knowledge management (KM) applied to a schooling context calls for a school to "develop a deep capacity among its entire staff to be at the forefront of knowledge and skill in teaching and learning" (2010, p. 622). However, she points to a dearth of literature on how indeed this "knowing" is informed, particularly in the context of the challenges faced in many school communities in South Africa (2010, p. 622). While Moloi (2010, p. 628) concentrates on what it might mean to develop a learning organization in such contexts (by, for example, working in teams and building feelings of belonging), this article hones in on how "knowledge management" is understood and experienced by the knowledge-

\footnotetext{
*Correspondency: norma.romm@gmail.com
} 
worker participants - namely, Teachers, Head of Departments (HoDs), administrative clerks, and principals.

In the management literature, effective management is linked to a concern with "doing right things" - that is, it denotes a concern with what should be done (and not on the how of accomplishing a task). The distinction between efficiency and effectiveness originates from Drucker's famous "The Effective Executive: The Definitive Guide to Getting the Right Things Done" (published in 1967, with additional editions in 1985, 1996, 2002, 2006). Drucker proposes this understanding of effectiveness as applying to both business and public organizations, but he recognizes that in different cultural milieux ways of defining decisions as being indeed the "right" ones can vary. For example, he refers (1971) to the Japanese ideal of consensual decision-making and how this may appear strange to certain Western executives. This is the cultural milieu in which Nonaka and colleagues developed their knowledge management $(\mathrm{KM})$ approach to knowledge creation and knowledge sharing towards defining "right" courses of action to be pursued (Nonaka, 1994; Nonaka, Byosiere, Borucki \& Konno, 1994; Nonaka \& Konno, 1998; Nonaka, Toyama \& Konno, 2000; Nonaka \& Toyama, 2003; Nonaka \& Takeuchi, 1995; Takeuchi \& Nonaka, 1986).

In outlining their view of KM, Nonaka and colleagues explain how $b a$, understood in the Japanese sense of the term as a platform for advancing individual and collective knowledge, implies the adoption on the part of knowledge creators of a "transcendental perspective" which becomes a "shared space" (not premised on individuals as separate selves). Murata (2012, p. 1536) notes that Shimizu (1995), on whom Nonaka and colleagues draw to a large extent, "highlighted the oneness of a human being and $b a$, noting that no human being can be separated from $b a$ and the others in $b a$ " (the shared space). This view of "selves" may be theorized in terms of what certain authors have suggested is a more group-oriented (collectivist-oriented) cultural orientation than manifest in "individualist" oriented cultures (cf. Brewer \& Venaik, 2011; Hofstede, 1984; Hofstede, Hofstede \& Minkov, 2010; Shulruf et al., 2011). We concur with Murata that it is important to understand Nonaka and colleagues' organizational knowledge creation theory "in the context of the socio-cultural background that pervades it" (2012, p. 1528). We also consider resonances with the African concept of Ubuntu, which too is based on a relational view of people-in-relation as conveyed in the expression (translated into English) "I am because we are" (e.g., Chilisa, 2020; Letseka, 2012; Maqutu, 2018; Mangena, 2012; Quan-Baffour \& Romm, 2015; Romm, 2017; Setlhodi, 2019, 2020). Setlhodi explains that "in Ubuntu-inspired projects ... those managing projects, together with others, "tap into African values and practices" in the spirit of "African co-operativeness" (Setlhodi 2019, p. 127). She argues that Ubuntu-infused leadership in school contexts can inspire people towards increased collaboration towards the enactment of shared goals (2019, p. 127). In the article we explore this notion further by examining how the participants commented (more or less critically) on the style of leadership that they detected in the schools and how it impacted on their experiences of KM in the schools (in relation to internal and external stakeholders).

\section{Effective and Ethical management: Ba and Ubuntu as a Potential Ethical Grounding for $K M$}

Based on their research work undertaken largely in Japan, Nonaka and colleagues propose their view of knowledge creation as a spiralizing process of interaction between people's tacit (know-how) and explicit (know why) knowledge. In this processs, people begin to share ideas through metaphors and through dialogue with a view to developing a synthesized mental model for the purposes of individual and collective action at different levels of the 
organization and in relation to the wider environment (e.g., Nonaka, Byosiere, Borucki \& Konno, 1994; Takeuchi \& Nonaka, 1995; Nonaka \& Konno, 1998). Nonaka and colleagues refer to four "knowledge conversion" processes with reference to what they call the SECI model. The $\mathrm{S}$ dimension of the model (Socialization) denotes a process where people learn from one another by being together in the same environment, sharing their tacit understandings through joint activities. The $\mathrm{E}$ in the model (Externalization) is a process whereby tacit understandings are converted into explicit articulations where people share ideas via metaphors and via dialogues, characterized by "listening and contribution to the benefit of all participants" (Nonaka \& Konno, 1998, pp. 43-44). The $\mathrm{C}$ in the model (Combination) involves converting knowledge into more complex sets of explicit knowledge via synthesizing and systemizing knowledge. This is the point at which new knowledge is spread amongst the organizational members, including in a form that is practically usable. In this phase, further justification of the "knowing" takes place as people develop agreements on the syntheses and their implications for action in relation to internal and external stakeholders. Internalization (the I letter in the model) enables the explicit knowledge from the $\mathrm{E}$ and $\mathrm{C}$ phases to be "embodied in action and practice" (Nonaka \& Konno, 1998, p. 45).

In terms of Nonaka and Konno summarizing of the phases of the SECI model, we could suggest that the model thus can be used to guide what Huff calls "thinking anew about knowledge that supports ethical/moral action" (2012, p. 2610). Huff considers that "knowledge creation" - no matter where it is practiced geographically and no matter in what type of organization - should never be removed from questions of ethics, because knowing is always linked to some form of goal creation: These goals should be reflected upon and "re-thought" as people in organizational life engage with one another's perspectives and concerns and take into account the larger environment of stakeholders in the community and society as a whole. Huff feels that Nonaka and colleagues have contributed an important addition to "thinking carefully about ethics and KM systems", so as to link decision making to "purposive moral action" (2012, p. 2611). He considers that one implication of Nonaka's theory of knowledge creation (which is not meant to be a morally-neutral theory) is that it foregrounds that

the ethical actor is not a passive recipient of a pre-packaged decision space. Instead he or she must shape the decision, and the organization, in light of proximate and long-term goals and imaginatively construct and implement solutions. (2012, p. 2611)

Huff feels that to date many KM initiatives taking place in the West (and those imported from the West into other geographical contexts) have not taken sufficiently on board the link between $K M$ and ethics as propounded by Nonaka and colleagues. This is not to say that the Japanese cultural milieu out of which Nonaka's model springs need be regarded as sacrosanct or as bereft of "unethical" potential. For example, Crawford (1998) suggests that the Japanese custom of tatemae encourages the painting of a "rosy, idealized picture of their country" and can become a "source of a great deal of confusion" when evaluating management ideas from Japan. Furthermore, it is not clear to what extent the collective spirit might enable a sense of connectivity outside of the borders of the Japanese society. Despite these caveats, we would suggest that we still need (as management theorists and practitioners) to take into account the value of a $b a$-inspired development of a "shared space", and to continue to explore its relevance for (ethical) KM. (See also Drucker, 1971.) This is particularly pertinent to our considerations with reference to the South African multiple case study, where, we argue, the concept of $b a$ can be seen to resonate with that of a we-directed commitment to Ubuntu.

In the context of both private and public organizations (such as public schools as our examples) 
we follow Harrison, Freeman, and Abreu (2015), who call on people to "rethink the responsibilities of the firm" in terms of ethical considerations. Harrison, Freeman, and Abreu suggest that a stakeholder theory is required that "advocates for treating internal and external stakeholders with fairness, honesty, and even generosity" (2015, p. 859). Our suggestion is that the kernel of Nonaka and colleagues' theory of $b a$ as encouraging the development of a shared space for defining common purposes, provides for this in principle, as does the philosophy of Ubuntu.

We deliberate further on this with reference to the selected public schools from South Africa, by pointing to Author2's research (2019-2020) in the three such schools including "primary", "secondary" and "combined" ones in a particular township (Emalahleni). (Primary schools serve children from ages 6-13; secondary ones from ages 14-18; and combined ones from ages 6-15.) As indicated above, a literature review of research on KM in South Africa indicates a paucity of documented body of work on KM where the schooling system is a focus of attention - with Moloi's (2010) and Kalema, Motsi and Motjolopane's (2016) work being exceptions. Meanwhile, on a global level, De Angelis remarks that indeed scant attention has been given to public sector KM more generally, and the few examples that exist do not "provide [sufficiently] rich data on the strategies and experiences of those engaged in the process at the organizational level" (2013, p. 8). Author2 set out to consider how KM could be said to be operative (more or less) in the various interactions between the internal stakeholders and with external ones in the three selected public schools. He was also keen to examine how, if at all, what Setlhodi (2019) calls the spirit of Ubuntu infused the KM practices.

\section{Method of Study}

Author2's main research question that he wished to explore was as follows: "In what regard is KM being applied at selected township schools?" One of his subquestions, on which we concentrate in this article, was: "In which ways do teachers, HODs, administrative clerks and principals draw on African Indigenous Values Systems of Ubuntu Philosophy and/or Batho Pele Principles to effect KM application at selected township schools?"

In order to delve into these questions (among others), he chose to work within a constructivist paradigm of social research - as defined by, for example, Lincoln and Guba (2013) - so that he could explore, together with participants, these questions using a qualitative research approach (in this case in-depth interviewing). As indicated above, 20 participants from three schools, occupying various positions in the schools (principals, HODs, teachers and administrators) were involved in the study. It was important to involve participants from all these levels so as to consider with the participants the extent to which, and ways in which, knowledge sharing across the positions was being instituted. It was also considered that a multiple case study (in this case involving three township schools) would enable comparison across various contexts. Below we discuss the sampling process, and we also comment upon the ethical approach adopted.

\section{Sampling of the Schools and the Participants}

As in other qualitative research sampling (Onwuegbuzie \& Leech, 2007) purposive sampling was used. Nkambule considered that the participants who would best serve the purpose of the study were teachers, HoDs, administrative clerks and principals, due to the richness of their experiences in relation to the topic of KM. He chose these participants from three schools in the three different Circuits of Emalahleni (servicing different ages of children) so that the township schools in Emalahleni were "represented" in some way. In qualitative 
research, "representation" of a population is not achieved through statistical means. Ultimately readers have to judge to what extent the results of the analysis from the three schools may extend beyond the sample identified (as in the criterion of transferability - cf. Anney, 2014; Chowdhury, 2015; Lincoln \& Guba, 2013). This judgement rests on the readers' familiarity with conditions in other schools and the ability to compare the richness of the discussion of the contexts in the three schools with other contexts (Flyvbjerg, 2006).

Schools were selected in accordance with circuit demarcations. Emalahleni (also known as Witbank) is demarcated into three circuits. This necessitated equal representation of all three circuits. On that basis one school from each of the three circuits was chosen to represent the wider population of other schools situated in that particular circuit. As far as the actual participant selection was concerned, the principals assisted in choosing suitable participants whom they felt would contribute favorably to the study, based on the criteria suggested by Nkambule. The selection process only affected teachers and HoDs because in that category, there were more than two employed in those schools. With regard to administrative clerks and principals, their numbers were limited to those employed in the respective schools (two of the schools were being serviced by two administrative clerks, and one school had only one administrative clerk that was gainfully employed).

Notably, within the schools, the size and constitution of the sample varied. In school two of the schools, it comprised of two teachers, two HoDs, two administrative clerks and one principal. In the third it comprised of two teachers, two HoDs, one administrative clerk (as opposed to two) and one principal. A total number of twenty (20) participants across all four categories of employment. Also noteworthy is that in one of the selected schools, Nkambule can be deemed to have been an "insider" researcher as he is a teacher in this school, where he has worked for over six years. (See Nkambule, 2020, for detail on how he saw role as a researcher in terms of the insider-outsider perspectives.)

\section{Ethical Approach in the Study}

While Nkambule followed the normal ethical protocol as prescribed by University of South Africa's College of Education research ethics committee, he additionally felt that he could develop a reciprocal relationship with the participants whereby they could benefit from reflecting further on the issues raised by him during the one-to-one interview encounters. The ethical requirement for research reciprocity has been raised by many Indigenous research methodologists (e.g., Chilisa, 2009, 2020; Mkabela, 2005; Ndimande, 2018) and also propounded by various relational-oriented methodologists (e.g., Gergen, 2020; Romm, 2018, 2020; Roth, 2018). Nkambule's questions posed to the participants were accordingly meant to be thought-provoking and stimulating. That is, he encouraged the participants to treat the interviews as an encounter from which they could develop their understandings of KM (which they may not prior to this research have reflected upon in depth), by now reflecting upon the issues as raised by Nkambule. Examples of their positive feedback in this regard can be found in Nkambule (2020, p. 16). Furthermore, in relation to the original research questions, he adopted Creswell and Poth's (2018, p. 55) suggestion that emergence in qualitative research can present an opportunity for the researcher to revisit the primary research questions/subquestions so that they better reflect the purpose of the study. With the benefit of hindsight, after having interviewed a principal and an HOD in the first school, Nkambule realized that two of the study's primary subquestions (about participants' leadership style) appeared to be too restrictive in composition; hence he refined them such that they put participants at liberty to characterize how they led KM initiatives in their school. 


\section{Analysis: An Abductive Process}

The results from the study were organized by analyzing them largely in terms of differences in the KM practices internally and in relation to external stakeholders. This is because Nkambule noticed when he asked questions relevant to Ubuntu and Batho Pele, that people offered responses that indicated that one could not speak overall about Ubuntu without considering the application in relation to internal and external stakeholders respectively. In this sense the analysis was generated from a close attention to how the various participants spoke about knowledge sharing within the organization and in relation to external stakeholders. Although Nkambule paid close attention to the expressions of the participants, we do not claim that the analysis was simply inductive (as is claimed many qualitative researchers who suggest that results can simply emerge through an inductive process. As noted by Kohn and Chistiaens (2018) "qualitative data analysis tends to be [defined as] inductive, which means that the researcher identifies categories in the data (p. 1); but they point out that "a qualitative research analysis can also ... [involve] predefined categories to which the data are coded" (p. 1). They consider the latter approach as a more deductive approach, with categories springing also from acquaintance with the literature.

However, aside from considering qualitative analysis in terms of an inductive/deductive distinction, we prefer to use the term abduction, along with authors such as: Bendassolli (2013); Reichertz (2019); Reiter (2017); and Romm (2018). When using the term abduction, it is recognized that the insights that arise from examining "the data" involve a logical leap which is neither inductive or deductive, but which enable interpreters to make sense of the data in a way that can be defended. This is consistent with Lincoln and Guba's constructivist credo (2013), where they admit that any analysis/interpretation is indeed a construction and cannot be read off from some presumed logical process of addressing "the data". We thus present the analysis/results below as insights that we believe can be gleaned from what people stated, while we cast new light on the way in which Ubuntu arguably became manifest in the various schools. With this in mind, we now turn to offering some of our constructed "results".

\section{Some Results Pertaining to the Operationalization of KM in the Three South African Schools}

Hereunder we consider some results pertaining to participants' accounts of KM application as they expressed these during the interview encounters and as we now make sense of them. We make sense of them as our synthesis of responses to Nkambule's questions regarding knowledge capturing and sharing in the schools and regarding the participants' understanding of the relevance of Ubuntu in this regard.

To start with, it is important to note that according to Perez-Soltero et al. (2019, p. 19), schoolwide KM application is a collective endeavor which is mainly intended for internally situated role players and partly for externally situated role players. Nkambule's study revealed that internal participants whom he interviewed in the three schools - teachers, HoDs, administrative clerks, and principals - were indeed aware of their expected roles in applying systematic methods to capture, retrieve, create and share knowledge. Although all participants used information technology (IT) to archive knowledge transactions (i.e. communications), administrative clerks were the ones who interfaced with IT more than other layers of staff. They used the software programme used in all South African Schools called South African School Administration Management System (SA-SAMS) to capture on data bases the report cards, registers, marks, leave management, and attendance, as well as information on the nutritional programme. In regard to the latter, two of the three schools were eligible for a national school 
feeding programme - namely, the primary and the combined school. In these two schools, where the national feeding system for learners was in place, the left-over food was also packaged into parcels to be distributed to learners' families, thus indicating a sense of additional social responsibility not only to learners but to their families in line with the values of relational accountability and caring. This undertaking exemplifies how, within socio-economically challenged spaces, Ubuntu-oriented KM application, also in relation to external stakeholders, can possibly present ethically responsive solutions.

Internally, administrators in all the schools spoke about the importance of email exchanges with all levels of staff within their schools in sending and receiving knowledge and developing shared understandings. Additionally, they referred to telephones and mobile phones as helping a great deal in exchanging knowledge. It can be said that their sense of the importance of developing shared understanding with staff resonates with Addleson's reference (2013, p. 33) to "a language of 'relationships', 'engagement', 'conversations', 'attitudes', and 'values' that is altogether more human than the other one" (which refers to codifying and storing data). On the whole, the administrators could thus be said to exhibit a relational mentality in their dealings with staff (as well as with external stakeholders).

Teachers and HoDs for their part largely depended on files (rather than IT systems) to record content knowledge related to their pedagogical activities. As far as administrative matters were concerned, principals used a combination of IT and manual filing to record knowledge on the operations of their respective schools to be shared with, for example, the district, provincial and national levels of the Departments of Education.

In order to communicate with the school community, Teachers, HoDs, administrative clerks and principals exhibited an equal reliance on social media such as Facebook and Whatsapp as a means to share knowledge in a coordinated way. Issues raised by community members via these media could become a basis for holding meetings at the school, and feedback from meetings was also offered using these media. Using these social media technologies constitutes a cyber space, that is, cyber or systemizing $b a$ whereby the sharing of explicit knowledge spreads to a wider audience - that is, involving also external stakeholders in this space (Nonaka $\&$ Konno, 1998, p. 47). In view of the notion of a shared space, Nkambule found that participants did consciously forward gestures of Ubuntu (a word they used interchangeably with Batho Pele, meaning "people first") as a means to share/transfer knowledge. These expressions of Ubuntu by teachers, HoDs and principals were offered mainly in dealings with external stakeholders, as explained below.

\section{Further Discussion}

To further our discussion of insights gleaned from the study, we refer in some detail to the difference in responses that Nkambule detected in relation to internal and external stakeholders in two of the schools; and we then turn to offer insights about the role of leadership in stimulating an internal Ubuntu-styled KM approach (along with an external one in relation to external stakeholders).

One of the questions that Nkambule asked during the interview encounters was posed as: "Do you sincerely believe that you embody the foundations of Africa's Indigenous values systems of Ubuntu and Batho Pele to effect meaningful knowledge sharing experiences with others? (Kindly tell me how you do this.)" Nkambule was aware that school-based public servants are expected to be bound by the Batho Pele White Paper to service members of the public with utmost respect and diligence (Public Services Commission, 2020). He therefore probed 
participants on how they apply the Batho Pele Principles and/or Ubuntu to enhance knowledge sharing transactions with internal and external members of the school community.

In two of the schools (the primary and combined ones) the participants referred primarily to applying Ubuntu and/or Batho Pele Principles to enhance knowledge sharing encounters mainly with external stakeholders (perhaps because of the idea that Batho Pele is more about serving communities and putting these people "first"). That is, the vast majority of the participants in these schools referred to the relationship with the wider community. For example, one of the teachers in the primary school referred to the school's role in spreading the values of Ubuntu to the broader sphere of the community. She mentioned the internal modus operandi of the school, whereby the school opened their facilities and shared their resources with the less fortunate surrounding schools.

Our school does practice Ubuntu. So I would say that we are open to the community to learn from us. Our community is not very interactive with each other, uhhhm but I believe that if you have a problem, someone can help you. So, in a sense we do share information and express our feelings with the communities that are situated in the next township. We have a good relationship with other schools so with that I say that we get along so we do practice Ubuntu for the fact that we can communicate with other schools in the community. Because we have better resources than them they come here for exam copies and they use our netball and soccer fields. We are friendly, we accommodate people, we are open to student teachers for their practical, we are open to different ministers coming to share their word. So I believe that we are open and receptive to the community. I assist student teachers because I do know how it is as a student teacher, you are often vulnerable. So I make sure that they know they can learn from someone who has been there. I always make sure they understand the system and assist with questions and answers wherever I can [Teacher].

The HoD of the same school cautioned, though, that displaying the spirit of Batho Pele and Ubuntu in the school via the displaying of pamphlets on school walls, could imply that it is only people in the "front office" who were meant to apply these principles. As this HoD said: "Most of the time we are just putting that pamphlet of Batho Pele in the front office as if they are the only people who are supposed to practice it". She put matters into further context by stating that as far as she was concerned, she tried to apply it herself (in relation to external stakeholders):

In reality everybody has to practice it. When I am the SMT member and I'm passing by the office and seeing a parent coming into the office not yet reaching there I need to greet that person and say how really can I help you before even taking that parent to registry.

The principal of the same school also referred to the need to practice the ethos of Ubuntu and offered some examples of this (as practiced by himself and the staff).

In the "combined" school, similar sentiments were expressed by the various participants who all offered examples of how they felt that Ubuntu was manifest, and who indicated how caring, compassion, and respect for others and their concerns were sought via various practices of knowledge creation and sharing with the community. As indicated in the section above, they referred to the way in which they used various social media to arrange for meetings with external stakeholders so that issues of concern to them could be discussed and solutions sought. The examples they offered were again primarily about dealings with external stakeholders. 
But what was significant in the study is that in the (secondary) school where the leader selfdefined himself during the interview as democratically inclined is that this seemed to permeate the view of knowledge sharing amongst the internal stakeholders too. During the interview the principal emphasized the importance of approachability and the development of a climate where staff felt that they could have forums to raise and discuss issues of concern in their daily practices to together seek satisfactory solutions (in the spirit of Ubuntu-type collaboration). The teachers who were interviewed in this school indicated that they appreciated the leadership approach of the principal and they confirmed that the collaborative spirit that he encouraged permeated the staff's dealings with and between internal stakeholders (amongst themselves and indeed with the learners). The teachers in that school felt that there was room for indeed creating and sharing knowledge as a collective knowing effort; and they also expressed that this extended to their way of dealing with the learners, such that according to them, learners too recognized that the teachers were approachable and open to discuss issues of concern.

In the other two schools on the other hand, the principals (when probed about their preferred leadership style) did not use terms that implied that they considered themselves as democratic leaders. For example, in the primary school the principal admitted that there was a "top-down" form of communication, albeit that he felt that this is not problematic as the "information" gets to where it is supposed to go. He commented:

Communication is good at our school and we sit and discuss things a staff and together we come make decisions. The organizational structure although we use top down approach but it does not bother us because information gets to where it is supposed to go. Yes, we do argue sometimes, eventually we set our differences aside.

When Nkambule moved to discussing the channels of communication with the teachers of the school, they expressed that issues of concern were getting "lost in the hierarchy" and furthermore teachers' inputs in decision-making seemed not to be considered by the SMT. They thus did not appreciate the top-down channels of communication and they contradicted the gist of the principal's narrations.

In the combined school likewise the principal had a more rosy picture than the teachers of how knowledge creation and sharing was operative. The principal in that school asserted:

I cannot say our communication is perfect but it works for us. I have competent HoDs who always inform teachers about everything that needs to happen in the school. In meetings we brief them on everything they need to know. I see that they [SMT members] get along as a team, which is the reason we are one of the best schools in the area. To prove this, eighty percent of my staff have been here for more than ten years. If they were unhappy with the school culture, I think they would have left one by one a very long time ago.

He felt that because the teachers had not changed schools, this was an indication that they were sufficiently satisfied with the functioning of the communication channels and the "school culture". Again this was not confirmed by the teachers who were interviewed, who felt that the communications did not reach desirable levels either in their communications "upwards" or in the formation of learning communities amongst the teachers.

In short, it emerged in two of the three schools (the primary and the combined school) that the higher levels of staff, i.e. HoDs and principals, were less concerned about sustaining Ubuntu in their internal dealings with other levels of staff. As a consequence, the principles of Ubuntu (which we indicated earlier can be compared with ba-type orientations) were applied 
selectively, in that these principles were operative more in the dealings with external stakeholders. In all the schools, the participants all expressed that they were aware of the role of the school in trying to uplift the community - and from their various expressions during the interviews it was apparent that Ubuntu principles of listening to concerns of parents and the wider community (including Educational Department officials) and seeking solutions for a "common cause" of community upliftment were sought. From the participants' various accounts Nkambule drew out several nouns (humanness, sympathy, openness, care, love and service, friendliness, approachability, partnership, courteousness, cheerfulness and attentiveness) which they mentioned to depict how they applied Ubuntu to facilitate knowledgesharing transactions. Another issue that came to the fore pertains to schools' awareness of their co-responsibilities with the community in reducing social disparities through transferring their knowledge for the greater benefit of surrounding communities. This was highlighted by some participants who mentioned how their respective schools would give guidance on how members of the communities can apply for social grants, handle domestic violence issues, and complete official documents.

\section{Insights Regarding Issues of Leadership}

One of the questions that Nkambule posed to principals from the various schools concerned their leadership style. He asked them to reflect upon this by asking: "How would you characterize your leadership style when dealing with KM application?" He also asked all the participants (including HoDs, teachers and administrators) to comment on whether they believe that "the organizational culture or environment enables Knowledge Management application to thrive". This was an opening for them to comment on the relations between the different levels of staff.

From the discussion in the section above, it is apparent that during the interviews with participants, the teachers from the primary and combined schools posited that they felt that the "collective spirit" associated with Ubuntu fizzled out whenever the superior staff (such as HoDs and principals) undermined their ideas/knowledge in matters relating to the development of the schools. The overriding concern expressed by teachers in these two schools was what they considered to be the one-way communication and ineffective leadership on the part of the school management teams (SMTs), where ineffectiveness was considered by the teachers as failing to institute two-way communication as a means of examining and solving issues to be addressed.

By contrast, in the secondary school, the leader self-defined himself as democratically inclined, and the leadership appeared to be distributed (Naicker \& Mestry, 2011, 2013; Williams, 2011). As Naicker and Mestry put it, distributed leadership becomes practiced as a "collective phenomenon" (2013, p. 2). In the school arguably characterized by this leadership style, KM application was remarked by all the interviewees to be systematically facilitated through mutual respect, collective engagements and high motivation levels, leading to both efficient and effective KM operations. Two-way communication ensured that there was no culture of "mistrust, frustration, confusion and rivalry" (to use the terminology of Nyembe-Kganye, 2005; and Rasebotsa, 2017) among all levels of staff in this school - that is, the secondary school.

The comparison of the three schools enables us to (abductively) comment on the role that leadership might play in impacting on the systematization of KM. We can extrapolate that the rigidity of the top-down approach (which is often synonymous with public sector organizations) can and should be (re)configured by public organizations such that it incorporates bottom-up 
initiatives, so as to allow bottom layers of staff to also play a participatory role. The study reverberates with Okeke and Okeke's (2016, p. 19) consideration of KM being "a set of processes that deals with collective understanding of optimizing knowledge activities ... which are relevant in their knowledge economy, as such, enhances their construction and use of knowledge".

\section{Conclusion}

In this article we considered the contours of effective and ethical KM with reference to a multiple case study involving three public schools in South Africa. We compared the Japanese concept of $b a$ as a basis for practicing KM (following the work of Nonaka and colleagues) with the African concept of Ubuntu. We pointed to (reported) instances in the schools that were studied of their incorporating Ubuntu into the schools' processes of KM. This was especially in relation to dealings with external stakeholders, so that KM became practiced in accord with community concerns. We indicated how in the development of sharedness (relationality or relational accountability) in external dealings with stakeholders, the instantiation of the African concept of Ubuntu could be regarded as having been at play to some extent in all the schools. And in the school where participants experienced the principal (and the principal self-named himself) as democratically inclined, it was manifested in the various participants' accounts of their dealings with one another and even with their learners.

We suggested, therefore, that leadership practices, such as operating in terms of a more democratic or distributive style of leadership, can be seen as playing a role in whether Ubuntu becomes practiced in the communications between internal stakeholders so that effective and ethical knowledge-creation for the benefit of learners can become better instituted. Legislators could use this study as the basis upon which to benchmark KM best practices, particularly in the public schooling arena and other public agencies. The study also has implications for future research, in terms of which prospective researchers can further investigate the practice of distributive leadership in facilitating knowledge sharing behavior among teachers, HODs, administrative clerks and principals in the school ecology.

\section{References}

Addleson, M. (2013). Will the real story of collaboration please stand up so we can see it properly. Knowledge Management Research \& Practice, 11(1): 32-40.

Anney, V. N. (2014). Ensuring the quality of the findings of qualitative research: Looking at trustworthiness criteria. Journal of Emerging Trends in Educational Research and Policy Studies (JETERAPS), 5(2): 272-281.

Bendassolli, P. F. (2013, January). Theory building in qualitative research: Reconsidering the problem of induction. Forum Qualitative Sozialforschung/Forum: Qualitative Social Research, 14(1).

Bratianu, C. (2012). A critical analysis of Nonaka's model of knowledge dynamics. Electronic Journal of Knowledge Management, 8(2): 193-200.

Brewer, P. \& Venaik, S. (2011). Individualism-Collectivism in Hofstede and GLOBE. Journal of International Business Studies, 42(3): 436-445.

Chilisa, B. (2009). Indigenous African-centred ethics: Contesting and complementing dominant models. In D. M. Mertens \& P E. Ginsberg (Eds.), The handbook of social research ethics (pp. 407-426). London: Sage.

Chilisa, B. (2020). Indigenous research methodologies (2nd ed.) London: Sage. 
Chowdhury, I. A. (2015). Issue of quality in a qualitative research: An overview. Innovative Issues and Approaches in Social Sciences, 8(1): 142-162.

Crawford, R. J. (1998). Reinterpreting the Japanese economic miracle. Harvard Business Review, 76(1): 178-183.

Creswell, J. W., \& Poth, C. N. (2018). Qualitative inquiry and research design (4th ed.). London: Sage.

De Angelis, C.T. (2013). Models of governance and the importance of KM for public administration. Journal of Knowledge Management Practice, 14(2): 1-18.

Drucker, P. F. (1971). What we can learn from Japanese management. Harvard Business Review (March 1971). https://hbr.org/1971/03/what-we-can-learn-from-japanesemanagement.

Drucker, P. F. (2002). The effective executive: The definitive guide to getting the right things done. New York: Harper Collins.

Drucker, P. F. (2004). What makes an effective executive? Harvard Business Review (June 2004) https://hbr.org/2004/06/what-makes-an-effective-executive.

Flyvbjerg, B. (2006). Five misunderstandings about case study research. Qualitative Inquiry, 12(2): 219-245.

Gergen, M. M. (2020). Practices of inquiry: Invitation to innovation. In S. McNamee, M. M. Gergen, C. Camargo-Borges \& E.F. Rasera (Eds.), The Sage handbook of social constructionist practice (pp. 17-23). London: Sage.

Harrison, J. S., Freeman, R. E., \& Abreu, M. C. S. D. (2015). Stakeholder theory as an ethical approach to effective management: Applying the theory to multiple contexts. Revista brasileira de gestão de negócios, 17(55): 858-869.

Hofstede, G. (1984). Culture's consequences: International differences in work-related values. London: Sage.

Hofstede, G., Hofstede, G. J., \& Minkov, M. (2010). Cultures and organizations: Software of the mind. New York: McGraw-Hill.

Huff, C. (2012). What does knowledge have to do with ethics? In G. J. M. Da Costa (Ed.), Organizational learning and knowledge: Concepts, methodologies, tools and applications (pp. 2604-2613). Hershey: IGI Global.

Kalema, B. M. M., Motsi, L., \& Motjolopane, I. M. (2016). Utilizing IT to enhance knowledge sharing for school educators in developing countries. The Electronic Journal of Information Systems in Developing Countries, 73(8):1-22.

Kohn, L., \& Christiaens, W. (2018). Inductive versus deductive approaches to research process. KCE Process Book. Accessed 1 November 2021 at: https://processbook.kce.fgov.be/.

Letseka, M. (2012). In defence of Ubuntu. Studies in Philosophy and Education, 31(1): 47-60.

Lincoln, Y. S., \& Guba, E. G. (2013). The constructivist credo. Walnut Creek, CA: Left Coast Press.

Mangena, F. (2012). Towards a Hunhu/Ubuntu dialogical moral theory. Phronimon, 13(2):1-7.

Maqutu, T. M. (2018). African philosophy and Ubuntu: Concepts lost in translation. Master's dissertation in Department of Jurisprudence in the Faculty of Law, University of Pretoria.

Mkabela, Q. (2005). Using the Afrocentric method in researching indigenous African culture. Qualitative Report, 10(1): 178-189.

Moloi, K. C. (2010). How can schools build learning organizations in difficult education contexts? South African Journal of Education, 30(4): 621-633.

Murata, K. (2012). Knowledge creation and sharing in Japanese organizations: A socio-cultural perspective on ba. In G. J. M. Da Costa (Ed.), Organizational learning and knowledge: concepts, methodologies, tools and applications (pp. 1528-1543). Hershey: IGI Global. 
Naicker, S. R., \& Mestry, R. (2011). Distributive leadership in public schools: Experiences and perceptions of teachers in the Soweto region. Perspectives in Education, 29(4): 99-108.

Naicker, S. R., \& Mestry, R. (2013). Teachers' reflections on distributive leadership in public primary schools in Soweto. South African Journal of Education, 33(2).

Ndimande, B. S. (2018). Unraveling the neocolonial epistemologies: Decolonizing research toward transformative literacy. Journal of Literacy Research, 50(3): 383-390.

Nkambule, B. I. (2020). Knowledge Management application in township schools: A case study of Emalahleni Circuit 1, 2 and 3. Doctoral thesis, Pretoria: University of South Africa.

Nonaka, I. (1994). A dynamic theory of organizational knowledge creation. Organization Science, 5 (1):14-37.

Nonaka, I., Byosiere, P., Borucki, C. C., \& Konno, N. (1994). Organizational knowledge creation theory: A first comprehensive test. International Business Review, 3(4): 337351.

Nonaka I \& Takeuchi H (1995). The knowledge creating company: How Japanese companies create the dynamics of innovation. New York: Oxford University Press.

Nonaka, I., \& Konno, N. (1998). The concept of "Ba": Building a foundation for knowledge creation. California Management Review, 40(3): 40-54.

Nonaka, I., Toyama, R., \& Konno, N. (2000). SECI, Ba and leadership: A unified model of dynamic knowledge creation. Long Range Planning, 33: 5-34.

Nonaka, I., \& Toyama, R. (2003). The knowledge-creation theory revisited: Knowledge creation as a synthesizing process. Knowledge Management Research and Practice, 1(2): 2-10.

Nyembe-Kganye, P. (2005). The chief superintendent of education management as a communication link between the districts and circuits of the Ethekwini region of the KwaZulu- Natal Department of Education and Culture. Doctoral Thesis, University of Zululand, KwaDlangezwa.

Okeke, V. O., \& Okeke, O. J. P. (2016). Advancing the Igbo language using elements of knowledge management: The role of academics in South Eastern Nigerian Universities. International Journal of African Society Cultures and Traditions, 4(4): 13-26.

Onwuegbuzie, A. J., \& Leech, N. L. (2007). Sampling designs in qualitative research: Making the sampling process more public. The Qualitative Report, 12(2): 238-254.

Perez-Soltero, A., Salcido-Flores, R., Ochoa-Hernandez, J. L., Barcelo-Valenzuela, M., Sanchez-Schmitz, G., \& Lopez-Muñoz, M. E. (2019). A methodological proposal to Manage Knowledge in the Organization of School Events. IUP Journal of Knowledge Management, 17(3): 19-43.

Public Service Commission (PSC) (2000). Survey with compliance with the Batho Pele policy. Retrieved on 14 May 2019 from<http://www.psc.gov.za/docs/reports/ 2000/survey/intro.pdf: 1-120>.

Quan-Baffour, K. P., \& Romm, N. R. A. (2015). Ubuntu-inspired training of adult literacy teachers as a route to generating "community" enterprises. Journal of Literacy Research, 46(4): 455-474.

Rasebotsa, D. (2017). How curriculum advisors and school management teams communicate curriculum changes in schools. Masters Dissertation, Pretoria: University of Pretoria.

Reichertz, J. (2019). The logic of discovery of grounded theory - an updated review. In A. Bryant \& K. Charmaz (Eds.), (pp. 214-228). The Sage handbook of current developments in grounded theory. London: Sage.

Reiter, B. (2017). Theory and methodology of exploratory social science research. University of South Florida Government and International Affairs Faculty Publications.

Romm, N. R. A. (2017). Researching Indigenous ways of knowing-and-being: Revitalizing relational quality of living. In P. Ngulube (Ed.), Handbook of research on theoretical 
perspectives on Indigenous knowledge systems in developing countries (pp. 22-49) Hershey, PA: IGI Global.

Romm, N. R. A. (2018). Responsible Research Practice. Cham: Springer.

Romm, N. R. A. (2020). Reflections on a post-qualitative inquiry with children/young people: Exploring and furthering a performative research ethics. Forum Qualitative Sozialforschung/Forum: Qualitative Social Research 21(1).

Roth, W-M. (2018). A transactional approach to research ethics. Forum Qualitative Sozialforschung / Forum: Qualitative Social Research, 19(3): Art. 1.

Setlhodi, I. I. (2019). Ubuntu leadership: An African panacea for improving school performance. Africa Education Review, 16(2): 126-142.

Setlhodi, I. I. (2020). Collaboration practices between the two tiers of school leadership in eradicating underperformance. South African Journal of Education, 40(3), https://doi.org/10.15700/saje.v40n3a1796.

Shimizu, H. (1995). Ba-principle: New logic for the real-time emergence of information, Holonics, 5(1): 67-79

Shulruf, B., Alesi, M., Ciochină, L., Faria, L., Hattie, J., Hong, F. \& Watkins, D. (2011). Measuring collectivism and individualism in the third millennium. Social Behavior and Personality, 39(2):173-187.

Takeuchi, H., \& Nonaka, I. (1986). The new product development game. Harvard Business Review, 64(1): 137-146.

Williams, C.G. (2011). Distributed leadership in South African schools: Possibilities and constraints. South African Journal of Education, 31(2). 